In his second paragraph Professor Oliver reacts strongly to a single brief paragraph in the text and one sentence of the summary that included speculation about the possible importance of the results. In each of the four sentences in question use of the subjunctive clearly implies caution, and the reader is referred back to our original paper, in which the speculations may be viewed in perspective. The paper contains no dietary recommendations, and, indeed, the only recommendations that I have espoused are those of the Committee on Medical Aspects of Food Policy panel on diet and heart disease ${ }^{1}$ and the study group of the European Atherosclerosis Society, ${ }^{2}$ of which Professor Oliver and I were both members.

J I MANN

Radcliffe Infirmary,
Oxford OX2 6HE

1 Advisory Panel of the Committee on Medical Aspects of Food Policy. Diet and coronary disease. London: HMSO, 1974. (Report on Health and Social Subjects No 7.)

2 Study Group of European Atherosclerosis Society. Strategies for the prevention of coronary heart disease: a policy for the prevention of coronary heart disease: a policy
statement of the European Atherosclerosis Society. Eur Heart $\mathcal{F}$ 1987;8:77-8.

\section{Effect of preoperative lactulose on posthaemorrhoidectomy pain}

SIR,-May I support the findings of Mr N J M London and colleagues (8 August, p 363) that a laxative regimen designed to produce early and frequent bowel actions after haemorrhoidectomy is beneficial to the patients.

In our study we compared our standard regimen of sterculia (Normacol) $10 \mathrm{ml}$ and liquid paraffin and magnesium hydroxide $B P C 10 \mathrm{ml}$ twice daily $(n=13)$ with concentrated extract of wheat husk (Trifyba, Labaz) one sachet three times a day $(n=17)$, starting immediately after surgery. ${ }^{1}$ Treatment was continued until patients were discharged from hospital, when their bowels were open comfortably and control had returned. The pain was assessed on a $100 \mathrm{~mm}$ linear scale after the first bowel action and after defecation on the third day after operation and on the day of discharge. No preoperative laxative or bowel preparation was given. Median pain scores (with interquartile range) on the third day after operation were: Trifyba 40 (21-70), sterculia and magnesium 50 (40-55). On the day of discharge pain was significantly less with Trifyba $(20(6-25) v 40$ $30-40), p<0.05)$. The pain scores for the third postoperative day were similar to those seen by $\mathrm{Mr}$ London and others.

We found no difference in the number of bowel actions on day 3 and on the day of discharge. Patients receiving Trifyba stayed in hospital for a shorter period (median stay in 4 (range 3-5) days compared with 5 (3-6) with sterculia and magnesium). Bleeding after defecation was equally common in both groups, but faecal leakage was seen more often in those taking sterculia and magnesium (10/13 patients compared with $5 / 17$; $\left.\chi^{2}=4.89, p<0.05\right)$.

We believe that the superior results with wheat husk are related to the production of a more "normal" stool, although the supposition that laxatives ease postoperative pain after haemorrhoidectomy by the production of a soft bulky stool has not been subjected to scientific investigation and must remain speculative. The authors have shown that preoperative administration of a laxative which produces soft bulky stools is beneficial in the postoperative period, and possibly we could improve our results by starting the wheat fibre preoperatively. Faecal leakage is a known complication of oil based laxatives, and the high incidence found in our study suggests that such oily agents should be avoided after haemorrhoidectomy.

Department of Surgery, Westminster Hospital London SWIP 2AP

1 Johnson CD, Budd J, Ward A. Laxatives after heamorrhoidectomy. Dis Colon Rectum (in press).

\section{How to take a teaching ward round}

SIR,-Dr John Rees (15 August, p 424) rightly emphasises the importance of the teaching ward round. In our medical school, however, achieving his optimum of three to five students and a willing patient is, regrettably, seldom possible. The chances of a nurse accompanying the teaching round have become remote indeed, as the nurses struggle to attend business rounds.

Over the past 10 years in our hospital the number of students has increased by almost half while the number of hospital beds from which to teach has fallen. The problem has become particularly critical in surgery over the past two years, when medical student training has unfortunately not been a consideration in the money saving exercises, which have resulted in ward closures, increased use of day surgery, and the more rapid turnover of surgical inpatients.

Unless government and hospital administrators begin to appreciate the serious effects their policies are having on medical training the time honoured teaching ward round is destined to disappear into medical folklore, and future generations of doctors will be deprived of a unique and valuable experience.

Nuffield Department of Surgery,

Alan R BerRy

John Radcliffe Hospital,

Oxford OX3 9DU

\section{Safer surgery for all}

SIR,-We were not surprised at the finding of Messrs K Lafferty and A P Wyatt (8 August, p 392) that "contamination incidents" occurred in up to half of all major general surgical operations. We have just completed a survey of 100 operations and general anaesthetics at the Royal Marsden Hospital, Fulham Road, during July. Operations were classified as major or minor, the minor group consisting mostly of breast biopsies and endoscopies. Anaesthetics were classified by the number of staff needed to give each anaesthetic (simple if three people or fewer; complex if more than three people). All staff at risk, including scrub nurses, assistants, and anaesthetic technicians, were included. The results are shown in the table.

Needlestick injuries occurred in 12 out of 42 major and 2 out of 58 minor operations. Less serious contamination incidents were common in major operations and complex anaesthetics needing more than three people. Our data suggest that the number of exposures might be reduced by anaesthetic staff regularly wearing gloves and by surgical and anaesthetic staff wearing eye protection-at least for major operations and complex anaesthetics.

Fortunately the risk of infection with human immunodeficiency virus is low, even after needlestick injuries. ${ }^{1}$ Our results are more relevant to the question of protecting operating theatre staff from hepatitis B infection, which is readily transmitted both by needlestick injuries and by contact between infected blood and cuts, open wounds, and conjunctival membrane. ${ }^{2}$ This is reflected in the rising incidence of acute hepatitis B infection among
Contamination incidents in 100 operations and anaesthetics at Royal Marsden Hospital (Fulham Road), fuly 1987

\begin{tabular}{|c|c|c|c|c|}
\hline \multirow{3}{*}{$\begin{array}{l}\text { Classification } \\
\text { No of cases } \\
\text { No of people "at risk" }\end{array}$} & \multicolumn{2}{|c|}{ Operations } & \multicolumn{2}{|c|}{ Anaesthetics } \\
\hline & Major & Minor & Comple & Simple \\
\hline & $\begin{array}{r}42 \\
186\end{array}$ & $\begin{array}{r}58 \\
159\end{array}$ & $\begin{array}{l}17 \\
71\end{array}$ & $\begin{array}{r}83 \\
197\end{array}$ \\
\hline $\begin{array}{l}\text { No wearing gloves } \\
\text { Gloves changed because of }\end{array}$ & 186 & 159 & 16 & 13 \\
\hline $\begin{array}{l}\text { cuts/tears } \\
\text { Blood on hands after } \\
\text { removing gloves }\end{array}$ & 15 & 0 & 0 & 3 \\
\hline $\begin{array}{l}\text { Not wearing gloves but } \\
\text { with blood on hands }\end{array}$ & & & 20 & 32 \\
\hline $\begin{array}{l}\text { Needlestick injuries } \\
\text { Blood on face }\end{array}$ & $\begin{array}{l}12 \\
17\end{array}$ & $\begin{array}{l}2 \\
2\end{array}$ & $\begin{array}{l}0 \\
6\end{array}$ & $\begin{array}{l}0 \\
1\end{array}$ \\
\hline
\end{tabular}

surgeons. ${ }^{3}$ These results support the BMA's view that active immunisation with hepatitis $B$ vaccine should be offered to all theatre staff. ${ }^{4}$ We would encourage hospitals where this is not yet standard practice to reconsider their policy urgently.

Michael Pittam

Hamish LaING NichOLAS HAL

Department of Surgery and Anaesthetics,

Royal Marsden Hospital

Fulham Road

London SW3 6JJ

1 McCray E. Occupational risk of the acquired immunodeficiency syndrome among health care workers. $N$ Englf $\mathrm{Med}$ 1986;314: 1127-32.

2 Anonymous. Update on hepatitis B prevention. Recommendations of the Immunization Practices Advisory Committee. MMWR 1987;36:353-66.

3 Polakoff S. Acute viral hepatitis B: laboratory reports $1980-4$ BrMed J 1986;293:37-8.

4 British Medical Association. Immunisation against hepatitis $B$. London: BMA, 1987. (Report of the board of science and education.)

Is screening for bacteriuria in pregnancy worth while?

SIR,-Just as medical rituals should not become sanctified by long usage, so hard won gains in preventive medicine should not lightly be discarded. Abandoning screening for bacteriuria in pregnancy has serious implications, not least medicolegal, for the antenatal care of women and their babies. It is therefore disconcerting that $\mathrm{Mr}$ I R McFadyen and Dr D V Seal (15 August, p 446) do not produce a detailed cost analysis. After all, this was the point of their thesis (20 June, $p$ 1579). The number of unavoidable cases of pyelonephritis is not really relevant. The real issue rests with a breakdown of the costs 1 -of screening and of the expense that would have been incurred in treating the six (not four) cases of pyelonephritis which were prevented. The authors reported seven cases of pyelonephritis at Northwick Park, so the costs of treatment should be available.

The additional information that $\mathrm{Mr}$ McFadyen and Dr Seal did provide appears contradictory. Six of their seven cases of pyelonephritis were originally reported thus: $1 / 226$ abacteriuric controls, $1 / 8$ with untreated bacteriuria, and 4/80 with treated bacteriuria. Despite other methodological detail, it is curious that suprapubic aspiration was not mentioned as the means of establishing the diagnosis, especially since two patients had sterile midstream urine specimens. By referring to a study by Kincaid-Smith, ${ }^{2}$ they implied that these two patients had "closed" renal infection. Kincaid-Smith, however, reported just one case (diagnosed by intravenous urography and nephrectomy) among 60 cases of pyelonephritis. The patients at Northwick Park, however, were not investigated radiologically. Presumably their diagnosis was based solely on a finding of low bacterial counts in bladder urine. Because only $0.005 \mathrm{ml}$ of urine was cultured and growth of any organism was considered "signifi- 